\title{
O REPERTÓRIO MUSICAL E A AÇÃO PEDAGÓGICA NA EDUCAÇÃO INFANTIL
}

THE MUSICAL REPERTOIRE AND THE EDUCATION IN KINDERGARTEN

\author{
Melita Bona \\ Mestre em Educação pela Universidade Regional de Blumenau \\ Professora do Departamento de Artes da Universidade Regional de Blumenau \\ E-mail: melitab@yahoo.com.br \\ Rozenei Maria Wilvert Cabral \\ Mestre em Educação pela Universidade do Estado de Santa Catarina \\ Professora do Departamento de Artes da Universidade Regional de Blumenau \\ E-mail: rozeneicabral@gmail.com
}

\section{RESUMO}

O artigo discute os resultados iniciais de uma investigação realizada por um grupo de professoras da educação infantil do município de Gaspar / Santa Catarina. As professoras, formadas em Pedagogia são integrantes de um grupo de estudos do Projeto Formação Continuada do Programa Institucional Arte na Escola - Polo da Universidade Regional de Blumenau / FURB, que envolve Artes Visuais, Música e Teatro. A partir das práticas nas diferentes linguagens artísticas realizadas nos encontros, as professoras se motivaram a investigar o tipo de repertório musical e o modo como a música é utilizada nos espaços de educação infantil do referido município. A pesquisa foi realizada em 2014 e partiu do próprio grupo, que vinha enfrentando desafios para trabalhar com a música nos espaços educativos, tendo em vista a ausência da formação específica em música. Provocadas por questões como: a falta de conhecimento e desvalorização da música local, a reprodução da música de cultura de massa e a falta de conscientização de professores em relação à diversidade e à qualidade da música ofertada às crianças, as professoras decidiram diagnosticar e identificar a realidade da escuta musical e do uso da música na prática pedagógica. Os dados parciais apontam para a presença da música na rotina pedagógica das professoras como coadjuvante de muitas tarefas e afazeres, bem como, fragilidades na formação do professor, que desvelam a importância do processo de formação continuada.

Palavras-chave: Repertório musical. Educação infantil. Formação continuada.

\begin{abstract}
This article reviews the initial results of a research developed by Kindergarten teachers from the city of Gaspar / Santa Catarina. Graduates in Education (BA), the teachers belong to a study group formed by Project Institutional Program Continuing Education Art School - Polo Regional
\end{abstract}


University of Blumenau / FURB, that includes Visual Arts, Music and Dramatic Arts. From exercises performed in the different areas of Arts during the meetings, the teachers were motivated to research what kind of music and how music was used in Kindergarten in their city. The research took place in 2014 and the initiative to develop the study came from the teachers themselves after many challenges to teach music in the classroom took place, mostly due to the lack of teacher's musical education. Questions like: the lack of knowledge and poor performance of the regional music, the reproduction of pop songs and the lack of teacher's understanding of the diversity and quality of the music played to children in the classroom; pushed the teachers to search and identify the reality of the teaching and listening of music in Kindergarten. The primary results show that music has a secondary role in many of the daily teachers' activities, and bring to light the teachers' lack of knowledge in this field, emphasizing the importance of continued education.

Keywords: Musical repertoire. Kindergarten. Continued education.

\section{INTRODUÇÃO}

O presente artigo aborda os resultados iniciais de uma pesquisa realizada em 2014, por um grupo de professoras da educação infantil do município de Gaspar, Santa Catarina tendo como temática o repertório musical e seus desdobramentos na prática pedagógica. A investigação foi realizada por iniciativa do próprio grupo, que vem enfrentando desafios para trabalhar com a música na educação infantil.

Formadas em Pedagogia, as professoras integram um grupo de estudos do Projeto Formação Continuada pertencente ao Programa Institucional Arte na Escola - Polo da Universidade Regional de Blumenau / FURB, cuja equipe de professoras orientou este trabalho.

O Projeto Formação Continuada, ativo desde 1993, está vinculado a Rede Arte na Escola, em nível nacional, com proposições de formação contínua de professores, para a comunidade interna e externa da FURB, envolvendo o campo da arte, em todos os níveis de ensino. Tendo como objetivo a qualificação de professores da educação básica e superior, mediante ações sistemáticas nas áreas de artes visuais, música, teatro e dança, o projeto contribui para a melhoria da prática pedagógica no ensino da arte, por meio de oficinas, grupos de estudo e pesquisa, assessoria na elaboração de projetos educativos e propostas curriculares, cursos de pósgraduação, seminários, encontros, entre outros. Alinhado aos pressupostos filosóficos e metodológicos dos Projetos Pedagógicos dos Cursos do campo da Arte, esta modalidade formativa se integra aos projetos Midiateca e Jogo Teatral na Escola do PIAE, além de outros programas e projetos de extensão da universidade. 
Vinculado à Pró-Reitoria de Pesquisa, Pós-Graduação, Extensão e Cultura, ao Centro de Ciências da Educação, Artes e Letras e ao Departamento de Artes, o Projeto Formação Continuada possui uma caminhada de 23 anos e faz parte da RAE - Rede Arte na Escola, via IAE - Instituto Arte na Escola de São Paulo, integrando universidades brasileiras que atuam com programas de pesquisa e educação continuada para professores, da rede pública e privada de ensino. Além de apresentar os primeiros dados da pesquisadas professores, o trabalho discute brevemente, as intercalações da formação continuada com a pesquisa e a formação do grupo de professoras e o modo como utilizam a música na sala de aula.

\section{FORMAÇÃO CONTINUADA E PESQUISA}

A formação continuada tem sido tema recorrente em discussões e reflexões nas diversas áreas do conhecimento, considerando as reformas curriculares movidas pelos novos tempos, paradigmas, leis, pareceres, parâmetros, entre outros.

O grupo de formação continuada da SEMED de Gaspar, realizado no PIAE desde 2009 vem ao encontro da Proposta Pedagógica da Educação Infantil da Rede municipal de Gaspar, pois, atende aos princípios preconizados pela Resolução $n^{0}$ 5, de 17 de dezembro de 2009, que fixa as Diretrizes Curriculares Nacionais para a Educação Infantil (BRASIL, 2010). No seu artigo $6^{\circ}$, o documento aponta que as propostas pedagógicas de Educação Infantil devem

respeitar os princípios éticos, políticos e estéticos e, em seu último inciso, refere-se à sensibilidade, criatividade, ludicidade e liberdade de expressão nas diferentes manifestações artísticas e culturais.

Assim, por meio desta modalidade formativa, constantemente vem-se buscando novos entendimentos sobre o ensino da arte. "A formação continuada não pode ser pensada num modelo fragmentado, às vezes desenvolvido em apenas um ou dois momentos ao longo do ano" (SCHOTTEN In SILVA; RAUSCH 2010, p. 105). Após a formação, o professor, necessita ter a possibilidade de esclarecer suas dúvidas, compartilhar suas dificuldades e angústias, pois, do contrário, pode ocorrer o que a autora chama de "formação descontinuada".

Deste modo, é possível iniciar um processo de mudança na prática pedagógica, que passa pela reflexão sobre o trabalho desenvolvido, elemento essencial no processo de formação, que rompe com um conhecimento sedimentado em rotinas e em ações automatizadas, reduzindo a reflexão e empobrecendo o pensamento sobre as bases de decisões. 
Resultante da reflexão sobre a ação, a formação continuada caracteriza-se como um processo em construção permanente. Segundo Rausch, “A reflexibilidade implica a imersão consciente do sujeito no mundo de sua experiência, um mundo carregado de valores, trocas simbólicas, interesses sociais, cenários políticos" (RAUSCH, 2010, p. 153).

No PIAE, a formação continuada tem sido canalizada, intencionalmente, para professores que atuam na Educação Infantil e que não possuem habilitação específica na área de arte, conforme ocorre com o grupo de professoras em foco.

A este respeito, Rosa Iavelberg (2003, p.51-52) menciona:

[...] nossa prática em formação de professores de arte aponta a necessidade de um processo de formação continuada. Mesmo que, a médio prazo, seja exigida formação universitária para o exercício profissional na Educação Infantil, e demais segmentos, a formação continuada é uma necessidade para educadores em serviços nas creches e escolas, uma vez que a atualização do professor precisa ser permanente.

A reflexão permanente sobre a prática docente no contexto da Educação Infantil busca a ampliação de repertórios em arte envolvendo as quatro linguagens, condição indispensável para consolidar uma educação inclusiva e de qualidade na área.

Considerar a importância que o campo da arte ocupa no processo do desenvolvimento infantil é responsabilidade dos professores formadores, que, abraçando com coragem este desafio que perpassa uma esfera legal, pedagógica e sensível, em que muitas vezes é preciso romper com as formas antigas que habitam as práticas, estão em eterna busca da melhor forma de conduzir os alunos para além do senso comum.

Para Rocha (2001, p.31), a problemática da formação do professor da educação infantil é evidente:

Se não do ponto de vista do ensino, pois não é objetivo da Educação Infantil ensinar conteúdos, o problema se coloca pelo menos do ponto de vista da formação dos professores de creche e pré-escola, pois a se considerar a multiplicidade de aspectos, saberes e experiências exigidos pela criança, coloca-se em questão quais domínios necessariamente devem fazer parte da formação do professor nesse âmbito.

Nas oficinas de música, a formação continuada prepara os professores para trabalhar com diferentes repertórios musicais. É necessário pensar práticas educativas para professores que atuarão com a música na escola, pois a eles compete desenvolver proposições com a música, em suas várias possibilidades. No entender de Bona,

O repertório musical da instituição escolar, hoje circundado por uma infinidade de tipos e gêneros musicais, não pode ser visto como fator ou objeto isolado. Justamente, pela amplitude do leque de produções musicais que atualmente se apresentam, considera-se fundamental que o professor saiba estabelecer critérios de escolha, ressaltando que os diferentes repertórios são vistos como complementares e não excludentes (BONA, 2006, p. 44). 
As ações de ensino e pesquisa são voltadas para a melhoria da prática pedagógica no campo da arte dos CDI, representando um avanço significativo no universo da sala de aula, envolvendo Música, Artes Visuais, Teatro e suas interfaces com o currículo, que oportunizam experiências significativas no processo de ensinar e aprender da arte.

Conforme Tardif (2012),

[...] o trabalho dos professores de profissão deve ser considerado como um espaço prático específico de produção, de transformação e de mobilização de saberes e, portanto, de teorias, de conhecimentos e de saber-fazer específicos ao ofício de professor (TARDIF, 2012, p. 234).

A pesquisa como princípio pedagógico na formação continuada possibilita que o professor seja protagonista na busca de respostas em um processo autônomo que envolve a ampliação de conhecimento e o acesso a novos repertórios para a sua prática pedagógica. Neste processo, o professor se situa como indivíduo real, concreto, da prática docente, dando voz à produção de conhecimento resultante do seu trabalho, rompendo com modelos tradicionais de ensino.

\section{AS PROFESSORAS E A PESQUISA}

O grupo constituído de 15 professoras, cada qual representante de um dos 15 centros de Centros de Educação Infantil municipais de Gaspar, SC, expressa a realidade atual da gestão (2014) da Secretaria de Educação/SEMED do referido município.

$\mathrm{O}$ que motivou as professoras a realizarem a pesquisa foram suas inquietações em relação à prática da música na educação infantil. Na ocasião, foram levantados alguns problemas pelo grupo como: falta de conhecimento da música produzida naquele município, desvalorização da música local, reprodução da música de cultura de massa, falta de conscientização de professores em relação à diversidade e à qualidade da música ofertada às crianças. A importância do projeto de pesquisa, para a formação de professores, considerando a obrigatoriedade do ensino da música na Educação Básica, é expressiva.

Considera-se importante frisar que estas questões foram detectadas pelas professoras, que, provavelmente sensibilizadas a partir das leituras e discussões realizadas no grupo de estudos, bem como, das reflexões após as práticas nas diversas oficinas. Uma vez conscientizadas da realidade do contexto no qual atuam, passam a sentirem-se incomodadas com 
o que observam no seu entorno e mobilizam-se para a realização da pesquisa. Aqui a pesquisa torna-se uma consequência da formação continuada, tendo como premissa a reflexão sobre a prática pedagógica.

Encontraram-se questionamentos similares em trabalhos que se aproximam da presente investigação. Diniz e Del Ben (2006, p.36) discutem a questão da música na educação infantil e detectam a necessidade da qualificação e fortalecimento da educação musical nesses espaços e, consequentemente, a necessidade de ser repensada a função da música nos currículos dos cursos de Pedagogia. As autoras apontam ainda para o significado dos cursos de formação continuada na área da música, para os professores unidocentes:

Os resultados revelam que as professoras têm buscado subsídios de várias formas, por iniciativa própria. Elas procuram fundamentar seu trabalho ampliando a sua formação, mas o fazem isoladamente. [...] Portanto, para melhorar e fortalecer a educação musical na educação infantil é necessário que aconteçam ações abrangentes (DINIZ e DEL BEM, 2007, p. 35).

Bellóchio (2014, p.49) volta seu olhar para a formação de professores unidocentes investigando "seus processos formativos no curso superior de Pedagogia, em seus conhecimentos musicais e pedagógico-musicais.” Segundo a autora “Assim, pensar na formação musical na Pedagogia requer mirar a complexidade do processo formativo que, por natureza, é de ordem da teoria e da prática. (BELLÓCHIO, 2014, P. 51). Da mesma forma, Correa (2014) discute a formação musical de professores de Pedagogia na perspectiva de não serem especialistas e trabalharem com a música na sala de aula. Para a autora,

O papel do unidocente, ao trabalhar com educação musical no universo infantil, é expandir o conhecimento de mundo, de culturas musicais diferenciadas daquela na qual ela está inserida, criando possibilidades de escuta, produção e execução musical. (CORREA, 2014, p.177)

A questão dos repertórios e das práticas musicais e o modo como a música é utilizada na educação infantil foram investigados por Bona (2006). A autora considera que as referências para escolha dos repertórios e atividades musicais estão ancoradas nos primeiros contatos com a música que as professoras tiveram na infância, seja em casa ou na escola.

$\mathrm{O}$ interesse das professoras pela pesquisa demonstra o comprometimento das mesmas com a prática pedagógica em arte, com crianças da Educação Infantil, que, de maneira peculiar, envolve os processos de formação e, consequentemente, os seus aspectos teórico-metodológicos que direcionam para diferentes vivências e contextos. 


\subsection{COLOCANDO A 'MÃO NA MASSA'}

Inicialmente, o projeto de formação continuada era coordenado por dois docentes da área de Artes Visuais da IES. Posteriormente, durante a análise e a discussão dos dados, o grupo passou a ser coordenado por uma docente de Artes Visuais e uma de Música.

Como objetivo geral, foi delineado realizar uma pesquisa de campo, para diagnosticar e identificar a realidade da presença da música na prática pedagógica dos demais professores dos CDI municipais de Gaspar.

Optou-se pelo questionário em razão de ser um instrumento apropriado para este tipo de pesquisa. Para Freire e Cavazotti (2007, p. 32), “Questionários e entrevistas são métodos voltados para o levantamento de informações prestadas por um depoente, e são muito ricos quando aplicados à pesquisa em música”. O questionário, constituído de 14 perguntas, foi organizado de forma mista, contendo questões abertas e fechadas e após sua elaboração, cada integrante do grupo de estudos aplicou o instrumento junto aos professores do CDI onde atua. Foram distribuídos 111 questionários para a esta coleta de dados. Todo o processo foi desenvolvido junto ao grupo de estudos e organizado em quatro etapas: elaboração do projeto e do questionário, aplicação do questionário, tabulação dos dados e análise quantitativa destacando-se que, o processo da análise qualitativa dos resultados continua em andamento.

A pesquisa se caracteriza por uma abordagem qualitativa e quantitativa, com análise dos dados dos questionários organizados em gráficos.

A abordagem qualitativa é privilegiada pela ótica dialética, embora procedimentos quantitativos sejam utilizados, não como um fim, mas como um ponto de partida para a interpretação da realidade, que, segundo a dialética, é necessariamente contraditória". (FREIRE E CAVAZOTTI (2007, p. 19).

Cabe ressaltar que o trabalho foi realizado de forma coletiva, por um grupo de professoras iniciantes no processo da pesquisa, sendo que nenhuma das componentes do grupo tinha experiências prévias nesta área.

Deste modo, a iniciativa abarcou aspectos diversos da formação continuada: a ampliação de um conhecimento específico - o repertório musical - a entrada no universo da iniciação científica e a disseminação de um espírito investigador no espaço da Educação Infantil, uma vez que a multiplicação dos questionários nos 15 CDI despertou o interesse e contaminou os demais professores das instituições.

A problematização levantada pelo grupo teve como conseqüência concreta a realização de uma série de oficinas práticas, direcionadas para o campo da arte, nas quais procuram ser contemplados aspectos apontados na pesquisa e com ações que poderão ser viabilizadas na sala de aula. 


\section{PRIMEIROS DADOS}

A coleta de dados resultou em 111 questionários respondidos e validados. Em alguns casos, no entanto, nem todas as questões foram respondidas. As primeiras duas questões visavam identificar os Centros de Educação Infantil e o tempo de atuação das professoras nesses espaços.

Na primeira resposta foram nomeadas 15 instituições municipais. Na segunda questão foram validados os dados de 109 questionários, sendo que os demais apresentaram mais de uma alternativa ou nenhuma.

Observa-se que $52 \%$ das professoras atuam no CDI entre 0 e 6 anos e $48 \%$ atuam ali entre 6 e 10 anos.

Tabela 1: Tempo de atuação das professoras dos CDI

\begin{tabular}{c|c|c}
\hline Tempo de atuação & Percentual & $\mathbf{N}^{0}$ de Pessoas \\
\hline 0 a 2 anos & $21 \%$ & 23 pessoas \\
\hline 3 a 6 anos & $31 \%$ & 34 pessoas \\
\hline 7 a 10 anos & $19 \%$ & 21 pessoas \\
\hline Mais de 10 anos & $29 \%$ & 31 pessoas \\
\hline
\end{tabular}

Fonte: dados da pesquisa das autoras

As questões que seguem tratam do uso da música, das referências e preferências do repertório musical no dia-a-dia da prática pedagógica das professoras.

Verificou-se que $99 \%$ das professoras utilizam a música na sua prática pedagógica sendo que, em 95\% dos casos isto ocorre de modo planejado e também espontaneamente.

Perguntadas sobre suas referências musicais na infância e durante a formação inicial, as professoras mencionaram uma série de gêneros musicais e estilos. Para esta questão foram validados os dados de 101 questionários, os demais não apresentaram resposta. Tratando-se de uma questão aberta, as professoras puderam responder livremente sobre suas preferências e referências musicais. Foram obtidas 240 opiniões.

Tabela 2: Referências musicais das professoras

\begin{tabular}{l|c|c}
\multicolumn{1}{c|}{ Gêneros musicais } & Percentual & $\mathbf{N}^{\mathbf{0}}$ de Pessoas \\
\hline Cantigas de Roda & $17 \%$ & 40 pessoas \\
\hline Palavra Cantada & $12 \%$ & 29 pessoas \\
\hline Xuxa & $7 \%$ & 16 pessoas \\
\hline Balão Mágico & $6 \%$ & 15 pessoas \\
\hline Sertanejo & $5 \%$ & 11 pessoas \\
\hline Infantil & $8 \%$ & 20 pessoas \\
\hline Outros & $45 \%$ & 109 pessoas \\
\hline
\end{tabular}

Fonte: dados da pesquisa das autoras 
Observa-se que as referências musicais mencionadas estão circunscritas aos repertórios da música infantil. Entende-se que pelo fato das professoras terem tido poucas oportunidades de formação na área de música, desconhecem a amplitude do universo musical.

O gosto musical, assim como as demais escolhas, constitui-se ao longo do tempo, faz parte do processo de socialização do indivíduo e está profundamente enraizado no habitus. [...]A idéia de habitus está vinculada ao que foi aprendido no passado, às normas, saberes e valores interiorizados, de maneira não consciente e que, ao mesmo tempo, "moldam" o indivíduo e o tornam reprodutor destes princípios. Ele se encontra na origem de suas ações e de outras propriedades que norteiam a sua conduta e o seu modo de compreender o mundo. (BONA, 2006, p.46).

Nesta perspectiva, não se desconsidera os saberes individuais do professor que, povoados de conteúdos cognitivos construídos ao longo da trajetória pessoal, em um processo contínuo de incorporação e transformação, que se desvelam na prática profissional (TARDIF, 2012).

No entender de Penna (2008), a música assume significados diferentes de acordo com cada cultura, pois sendo uma linguagem cultural,

[...] consideramos familiar aquele tipo de música que faz parte de nossa vivência; justamente porque o fazer parte de nossa vivência permite que nós nos familiarizemos com os seus princípios de organização sonora, o que torna uma música significativa para nós. (PENNA, 2008, p. 21)

Em outra questão, pretendia-se conhecer de que modo a música está integrada à rotina pedagógica das professoras. Para esta questão foram validados os dados de 111 questionários e, com base nos itens assinalados, foram obtidas 294 opiniões.

Tabela 3: A música na rotina pedagógica das professoras

\begin{tabular}{l|c|c}
\multicolumn{1}{c|}{ Atividade } & Percentual & $\mathbf{N}^{\mathbf{0}}$ de Pessoas \\
\hline Acolhida & $15 \%$ & 44 pessoas \\
\hline Descanso & $17 \%$ & 49 pessoas \\
\hline Saída & $7 \%$ & 21 pessoas \\
\hline Trabalho & $21 \%$ & 62 pessoas \\
\hline Interação & $16 \%$ & 47 pessoas \\
\hline Todo o tempo & $16 \%$ & 48 pessoas \\
\hline Outros & $8 \%$ & 23 pessoas \\
\hline
\end{tabular}

Fonte: dados da pesquisa das autoras

Além dos itens assinalados, foram mencionadas outras situações em que a música é utilizada. Verifica-se que a música é incluída de modo diversificado na prática das professoras e que, na maioria dos casos, está vinculada a outros afazeres como a hora das refeições, a roda de conversa, as brincadeiras de roda e momentos variados. Os dados remetem à pesquisa de Diniz $\mathrm{e}$ Del Ben (2007, p.33): 
A falta de conhecimento musical sistematizado faz com que as professoras encontrem dificuldades para estabelecer conteúdos e objetivos musicais e, assim, ampliar e diversificar as atividades que realizam.

Com relação ao gênero musical utilizado pelas professoras, foram obtidos na pesquisa 56 exemplos de clássicos, 52 de música popular, 165 de infantil, 26 de folclórico, 23 de outros estilos. Em outro momento, ao serem questionadas sobre a preferência de gêneros musicais, as professoras, em sua maioria, mencionam o gênero infantil como um dos primeiros, em grau de importância.

Para Maurice Tardif, a trajetória escolar pessoal permanece impregnada nos saberes e na prática do professor. Segundo o autor, “[...] muitas pesquisas mostram que esse saber herdado da experiência escolar anterior é muito forte, que ele persiste através dos tempos e que a formação universitária não consegue transformá-lo nem muito menos abalá-lo" (TARDIF, 2012, p.20). De certo modo, as professoras replicam na prática pedagógica os elementos constituintes do seu habitus.

Não é possível falar das preferências de repertório sem falar no gosto musical, pois é o gosto que orienta as escolhas de cada um. Segundo Bourdieu (1983, p. 131),

Compreender os gostos, fazer a sociologia dos gostos que as pessoas têm, de suas propriedades e suas práticas é, portanto, por um lado conhecer as condições em que se produzem os produtos oferecidos e por outro as condições em que os consumidores são produzidos.

Sobre esta questão Bona considera que, "A preferência por esta, ou aquela música não se dá 'por um acaso', [...] e, muitas vezes, o sujeito não se dá conta de quando e de que forma se estabelece o vínculo, a empatia e conseqüentemente, a decodificação de determinados códigos (BONA, 2006, p.74).

Para Dallabrida,

[...]o termo formação musical é amplo e abrange as diferentes experiências destes professores com a Música, sendo ingênuo desconsiderar suas internalizações musicais decorrente dos modos de fazer música em família, na escola enquanto alunos, no seu meio social, dentre outros $(2014$, p.4).

$\mathrm{Na}$ Educação Infantil a música é praticada de diferentes formas e em diversas práticas pedagógicas, geralmente de forma lúdica e cantada, padronizada e sem grandes pretensões pedagógicas em relação ao conteúdo musical utilizado. Os professores sem formação específica na área, na maioria das vezes, propõem atividades envolvendo a música como sendo um dos componentes, isto é, ações com música. O professor de música poderá realizar aulas de música, ou seja, contemplando aspectos musicais mais específicos. Considera-se que estas ações podem, ou deveriam ser complementares e, na sua configuração ideal, pertencentes a um mesmo projeto. 


\section{BREVES CONSIDERAÇÕES}

Em meio às dificuldades e aos problemas tantos com os quais se esbarra no campo da Educação, deparar-se com um grupo de professoras formadas em Pedagogia, que, motivadas pelos estudos de uma formação continuada, decidem investigar a música que é realizada nos espaços da educação infantil, vem a ser um alento.

Ao perceberem suas carências e lacunas formativas instalou-se no grupo, o processo de reflexão na ação, no sentido de vislumbrar a melhoria na qualidade da própria prática. Assim, é possível dizer que a iniciativa das professoras agregou aspectos significativos ao projeto de formação continuada.

Verifica-se que a música está presente na rotina pedagógica das professoras como coadjuvante de muitas tarefas e afazeres. Além dos dados referentes aos repertórios de escuta e do modo de utilização da música nas práticas pedagógicas, a pesquisa aponta também para o papel da formação continuada do professor de Pedagogia no campo da Arte.

Apesar de serem apresentados apenas dados parciais da pesquisa, foram detectadas fragilidades que apontam para a importância do processo de formação continuada, no sentido de suprir tais carências. Se por um lado os dados apresentam fragilidades, por outro, as professoras têm ciência dessa questão. Por essa razão, demonstraram interesse em realizar a pesquisa, para posteriormente viabilizar projetos educativos em música, com o intuito de fortalecer e instrumentalizar a prática pedagógica na área.

$\mathrm{O}$ interesse e envolvimento com a pesquisa mobilizado entre as demais professoras atuantes nos quinze CDI do referido município, a partir da distribuição dos questionários, pode ser considerado um dos aspectos positivos neste trabalho. Este fator consolida a indissociabilidade entre a extensão e a pesquisa.

A música está diretamente relacionada à cultura das pessoas, em diferentes épocas, e o gosto por ela pode mudar de acordo com as influências do meio de interação com o ambiente, mediante experiências vivenciadas nesse contexto. É uma expressão social e cultural que comprovadamente influencia no desenvolvimento da criança e tem sido destacada como uma das áreas de conhecimento mais relevantes a ser trabalhada na Educação Infantil.

\section{REFERENCIAS}

BELLOCHIO, Claudia Ribeiro. Educação básica, professores unidocentes e música: pensamentos em tríade. In Educação musical e pedagogia: pesquisas, escutas e ações. Claudia Ribeiro Bellochio, Luciane Wilke Freitas Garbosa (Org.). Campinas/SP: Mercado de Letras, 2014. 
BONA, Melita. Nas entrelinhas da pauta: repertório e práticas musicais de professoras dos anos iniciais. 2006. 138 f. Dissertação (Mestrado em Educação). FURB. Universidade Regional de Blumenau/SC.

Brasil. Ministério da Educação. Secretaria de Educação Básica. Diretrizes curriculares nacionais para a educação infantil/ Secretaria de Educação Básica. - Brasília: MEC, SEB, 2010.

BOURDIEU, Pierre. Questões de sociologia. Tradução de JeniVaistsman. Rio de Janeiro: Marco Zero Ltda., 1983.

CORREA, Aruna Noal. Não há como estar em uma sala de aula de educação infantil sem brincar sonoramente com as crianças: a formação musical e pedagógico-musical de professoras unidocentes. In: Educação Musical e Pedagogia: pesquisas, escutas e ações. Claudia Ribeiro Bellóchio e Luciane Wilke Freitas Barbosa (Org.). Campinas/SP: Mercado de Letras, 2014.

DALLABRIDA, Iara Cadore. Formação musical no curso de pedagogia: (des)afiando o professor unidocente. Iara Cadore Dallabrida. X ANPED SUL, Florianópolis, outubro de 2014. Disponível em: http://xanpedsul.faed.udesc.br/arq pdf/1820-0.pdf

DINIZ, Lélia Negrini; DEL BEN, Luciana. Música na educação infantil: um mapeamento das práticas e necessidades de professoras da rede municipal de ensino de Porto Alegra. Revista da ABEM, Porto Alegre, V. 15, 2006.

FREIRE, Vanda Lima Bellard. Pesquisa em música: novas abordagens. Vanda Lima Bellard Freire; André Cavazotti. Belo Horizonte: Escola de Música da UFMG, 2007.

IAVELBERG, Rosa. Para gostar de aprender arte: sala de aula e formação de professores. São Paulo: Artmed, 2003.

PENNA, Maura. Dó, ré, mi, fá e muito mais: discutindo o que é música.Música(s) e seu ensino. Porto Alegre, Sulina, 2008.

RAUSCH, Rita B. Reflexibilidade e pesquisa: articulação necessária na formação inicial de professores. In: SILVA, Neide de Melo A.; RAUSCH, Rita B. (Orgs.) Formação de professores: políticas, gestão e práticas. Blumenau: Edifurb, 2010.

ROCHA, Eloisa Acires Candal. A pedagogia e a educação infantil. In: Revista Brasileira de Educação: Abril $2001 \mathrm{~N}^{\mathrm{o}} 16$.

SCHOTTEN, Neuzi. Uma análise da formação do professor alfabetizador no município de Pomerode/SC. In SILVA, Neide de M. A.; RAUSCH, Rita B. (Orgs.). Formação de professores: políticas, gestão e práticas. Blumenau: Edifurb, 2010.

TARDIF, Maurice. Saberes Docentes e Formação Profissional. 14a Edição. Petrópolis, RJ: Vozes, 2012. 